\title{
Ranking provinces based on development scale in agriculture sector using taxonomy technique
}

\author{
Shahram Rostampour ${ }^{*}$
}

Department of Management Science, Islamic Azad University, Central Branch, Tehran, Iran

\begin{tabular}{|c|c|}
\hline ART I C L E I N F O & A B S T R A C T \\
\hline $\begin{array}{l}\text { Article history: } \\
\text { Received December 18, } 2011 \\
\text { Received in Revised form } \\
\text { February, 20, } 2012 \\
\text { Accepted } 28 \text { March } 2012 \\
\text { Available online } \\
\text { April } 62012 \\
\text { Keywords: } \\
\text { Ranking } \\
\text { Taxonomy }\end{array}$ & $\begin{array}{l}\text { The purpose of this paper is to determine comparative ranking of agricultural development in } \\
\text { different provinces of Iran using taxonomy technique. The independent variables are amount of } \\
\text { annual rainfall amount, the number of permanent rivers, the width of pastures and forest, } \\
\text { cultivated level of agricultural harvests and garden harvests, the number of beehives, the } \\
\text { number of fish farming ranches, the number of tractors and combines, the number of } \\
\text { cooperative production societies, the number of industrial cattle breeding and aviculture. The } \\
\text { results indicate that the maximum development coefficient value is associated with Razavi } \\
\text { Khorasan province followed by Mazandaran, East Azarbayjan while the minimum ranking } \\
\text { value belongs to Bushehr province. }\end{array}$ \\
\hline
\end{tabular}

Comparative development

Data Envelopment Analysis

\section{Introduction}

During the past few years, there has been an increasing concern on efficiently using foods in the world. From one side, we see a steady growth on the population of the world and on the other side, we see a decline on water supply, food and energy, which means we may face with serious problems of food supply within the next few decades. There is no doubt that food crises will be one of the upcoming events and human being need to invest more on optimum usage of agricultural lands and water supply. A relatively efficient land could produce more food, which reduces the risk of poverty in the world. For years, there have been tremendous efforts on proposing different methods based on multi criteria decision making (MCDM) to measure the relative efficiency of agricultural products.

Data envelopment analysis (DEA) is one of the most popular models for measuring the relative efficiency of various units. In DEA, there are normally more than one single input/output and it is possible to measure the relative efficiency of similar units based on non-financial figures. Mao and Koo (1997) used DEA method to measure productivity growth, technological progress, and efficiency

* Corresponding author. Tel: +989359821267

E-mail addresses: shahram Rostampour <shrrsp@yahoo.com (S. Rostampour) 
change in Chinese agriculture after rural economic reforms. They used 29 provinces in China and classified them into advanced-technology and low-technology categories. The Malmquist productivity measures were decomposed into two groups of technical and efficiency change index. The results indicated that total factor productivity had risen in most provinces for both technology categories during the 1984-1993 period. Technical progress was mostly attributed to Chinese agricultural productivity growth after the rural economic reforms. The deterioration in technical efficiency in many provinces indicated China had great potential to improve productivity through improved technical efficiency. Sueyoshi (1999) used DEA for meaning the ranking Japanese agriculture cooperatives.

Martić and Savić, G. (2001) presented an application of DEA for comparative analysis and ranking of regions in Serbia with regards to social-economic development. In their DEA implementation, they tried to estimate how well regions in Serbia utilize their resources. They used data for four inputs and four outputs and reported that 17 out of 30 regions were efficient. For each inefficient unit, DEA determined the sources and level of inefficiency for each input/ output. Picazo-Tadeo et al. (2011) used DEA for assessing farming eco-efficiency for both farm and environmental pressure-specific levels. The study computed for a sample of Spanish farmers operating in the rain-fed agricultural system of Campos County. The results disclosed that farmers were quite eco-inefficient, with very few differences coming from specific environmental pressures. In addition, eco-inefficiency was associated with technical inefficiencies in the management of inputs. Farmers benefiting from agrienvironmental programs as well as those with university education indicated to be more eco-efficient.

Hu et al. (2006) argued that water is a limited and unevenly distributed resource in China, with the per capita amount of water resource there only about one-fourth of the world's average. As we also explained earlier, water is an essential resource for people's lives and economic development anywhere in the world including China and effective water supply is definitely important for the sustainable development of human beings. They analyzed water efficiency by using water as an input as well as using traditional inputs such as labor employment and capital stock. They used an index of a water adjustment target ratio (WATR) from the production frontier constructed by DEA including water as an input. They reported that the central area had the worst water efficiency ranking and the total adjustment amount of water used there was around three-fourths of China's total.

Chen and Song (2009) utilized a unique county-level dataset to study technology gap and technical efficiency in China's agriculture. They classified the counties into four regions based on distinctive levels of economic development, and production technologies. They reported that the eastern counties had the highest efficiency scores with respect to the regional frontier but the northeastern region led in terms of agricultural production technology nationwide. Meanwhile, the mean efficiency of the northeastern counties was relatively low, recommending technology and knowledge diffusion within region might help to improve production efficiency and agricultural output. Hoang and Rao (2010) provided sustainable efficiency in agricultural production using a cumulative exergy balance approach.

One of the issues on the implementation of DEA is that there may be more than one single efficient units in a particular province and we need to use so called super efficiency techniques to repeat measuring the relative efficiency among efficient ones. Sadjadi et al. (2011) used DEA for measuring the relative efficiency of different gas distribution companies operating in various provinces of Iran. In their method, they developed an interactive super-efficiency DEA, which made it possible to better handling the supper-efficiency issue.

Murshed-E-Jahan and Pemsl (2011) presented an empirical study on the impact of integrated aquaculture-agriculture on small-scale farm sustainability and farmers' livelihoods in Bangladesh. They reported that the training had a significant positive impact on farmers' technical efficiency, net incomes and total factor productivity. 
Sultana and Kumar (2012) developed an MCDM technique to rank various biomass feedstock-based pellets, in terms of their suitability for use in large heat and power generation plants and demonstrated the relative importance of economical, environmental and technical factors in making decision about various pellets. Five pellet alternatives of wood, straw, switchgrass, alfalfa and poultry litter were ranked according to eleven criteria, using the Preference Ranking Organization Method for Enrichment and Evaluation (PROMETHEE). Both quantitative and qualitative criteria were used including technical, environmental and economic factors. Three scenarios, namely base case, environmental and economic, were developed by changing the weight assigned to various criteria. Based on the PROMETHEE rankings, wood pellets were the best source of energy for all scenarios followed by switchgrass, straw, poultry litter and alfalfa pellets except economic scenario, where straw pellets represented higher position than switchgrass pellets. Reith and Guidry (2003) tried to integrate piecemeal environmental improvements into a farm-wide program of systematic improvement and reported that eco-efficiency defined as 'the efficiency with which receivables could be converted into deliverables', was a suitable way to apply the lessons of industry to the agricultural sector.

In this paper, we present an empirical study to rank different provinces of Iran in terms of agricultural factors using Taxonomy method, which is an MCDM technique. The organization of this paper first presents details of the implementation of the proposed model in section 2 . Section 3 presents the results of our survey and finally section 4 summarize the contribution of this paper.

\section{Problem statement}

Taxonomy is one of the most popular MCDM techniques used for ranking existing alternatives based on development level by using matrix of alternatives and attributes relationship.

In this approach, first a data matrix is formed which consists of $n$ alternatives and $m$ attributes, which contrast with each such that $X_{i j}$ indicates value of $j$ th feature in ith attribute, and then by calculating mean and standard deviation (SD), we proceed to data normalization and compute compound distances between alternatives as follows,

$$
D_{a b}=\sqrt{\sum_{j=1}^{m}\left(Z_{a j}-Z_{b j}\right)^{2}} .
$$

We also determine upper and lower acceptance limits and remove out of range alternatives, and finally specify development level of any alternative as follows,

$$
\begin{aligned}
& C_{i o}=\sqrt{\sum_{j=1}^{m}\left(Z_{i j}-D_{o j}\right)^{2}}, \\
& F_{i}=\frac{C_{i o}}{C_{o}},
\end{aligned}
$$

Where

$\mathrm{D}_{\mathrm{ab}}$ : compound distance between alternatives,

$\mathrm{C}_{\mathrm{io}}$ : development pattern of any alternative,

$\mathrm{D}_{\mathrm{oj}}$ : positive ideal value,

$\mathrm{C}_{0}$ : upper limit of development,

$\mathrm{Z}_{\mathrm{ij}}$ : normalized feature,

$\mathrm{F}_{\mathrm{i}}$ is development level of any alternative. 


\section{Case study}

The purpose of this study is to determine the provinces' development ranking by using indices including annual rainfall amount, the number of permanent rivers, the width of pastures and forest, cultivated level of agricultural and garden harvests, the number of beehives, fish farming ranches. We also consider the number of tractors and combines, the number of cooperative production societies and industrial cattle breeding and aviculture. It is worthy of mention that all country's provinces have been considered as dependent variables. Table 1 shows the summary of primary data for entering to model (data source: statistics of agriculture jihad ministry, 2010).

Based on the accomplished modeling after implementing cited technique and doing computations to determine comparative development level, the rank of any province has been calculated, which is summarized in Table 2.

Table 1

Primal data problem

\begin{tabular}{|c|c|c|c|c|c|c|c|c|c|c|c|c|c|c|}
\hline Row & province & 1 & 2 & 3 & 4 & 5 & 6 & 7 & 8 & 9 & 10 & 11 & 12 & 13 \\
\hline 1 & East Azarbayjan & 285 & 78 & 2473440 & 188075 & 737126 & 114610 & 607443 & 359 & 25485 & 424 & 45 & 512 & 268 \\
\hline 2 & West Azarbayjan & 364.4 & 13 & 2516584 & 174000 & 722893 & 108239 & 527762 & 342 & 36360 & 675 & 21 & 450 & 26 \\
\hline 3 & Esfahan & 210 & 28 & 6270213 & 446380 & 280923 & 79134.72 & 511994 & 434 & 17773 & 381 & 42 & 2389 & 140 \\
\hline 4 & Ilam & 257.6 & 21 & 1112358 & 641667 & 251123 & 4555 & 24218 & 128 & 3999 & 106 & 72 & 74 & 2 \\
\hline 5 & Ardebil & 257 & 20 & 1015000 & 53193 & 685491 & 33123 & 144080 & 163 & 17020 & 951 & 19 & 208 & 22 \\
\hline 6 & Bushehr & 110 & 3 & 1211525 & 257069 & 222023 & 40986.1 & 17257 & 80 & 3619 & 43 & 33 & 169 & 1 \\
\hline 7 & Tehran & 185 & 36 & 1256400 & 76420 & 194154 & 82041 & 85410 & 151 & 4605 & 476 & 59 & 3329 & 230 \\
\hline 8 & Bakhtiari & 479 & 20 & 1093000 & 335000 & 147473 & 46612 & 91599 & 220 & 6267 & 40 & 26 & 329 & 6 \\
\hline 9 & North Khorasan & 165.5 & 47 & 1025941 & 408915 & 249452 & 37767.8 & 37242 & 74 & 8096 & 177 & 104 & 198 & 1 \\
\hline 10 & Razavi Khorasan & 225.1 & 42 & 6566029 & 996156 & 652925 & 237470 & 75303 & 543 & 22966 & 569 & 151 & 2314 & 226 \\
\hline 11 & South Khorasan & 134 & 3 & 6214464 & 606176 & 173800 & 53718 & 5798 & 222 & 4212 & 79 & 27 & 283 & 15 \\
\hline 12 & Khozestan & 393 & 6 & 2488608 & 947842 & 1212975 & 63787 & 52052 & 294 & 13826 & 372 & 47 & 345 & 6 \\
\hline 13 & Zanjan & 300 & 9 & 1137060 & 97553 & 431932 & 39024 & 73923 & 183 & 11097 & 304 & 21 & 141 & 16 \\
\hline 14 & Semnan & 135 & 5 & 3741386 & 352245 & 113479 & 34571 & 23146 & 142 & 2176 & 54 & 18 & 1000 & 23 \\
\hline 15 & Sistan & 101 & 4 & 10565100 & 1000000 & 150702 & 69903 & 939 & 554 & 6370 & 49 & 25 & 74 & 1 \\
\hline 16 & Fars & 5382.2 & 72 & 7309242 & 2215689 & 710477 & 354461 & 225076 & 297 & 6320 & 510 & 160 & 1442 & 28 \\
\hline 17 & Qazvin & 272.8 & 6 & 853485 & 28000 & 220634 & 75443 & 39195 & 166 & 1560 & 142 & 11 & 405 & 35 \\
\hline 18 & Qom & 177.3 & 2 & 72319 & 13275 & 49994 & 17045 & 15000 & 203 & 1767 & 86 & 25 & 574 & 113 \\
\hline 19 & Kordestan & 422 & 50 & 1361660 & 373326.2 & 74168 & 346360.063 & 103310 & 162 & 20516 & 834 & 96 & 96 & 7 \\
\hline 20 & Kerman & 126 & 41 & 9275049 & 2531247 & 261946.6 & 482615.2 & 66284 & 235 & 14831 & 104 & 154 & 642 & 17 \\
\hline 21 & Kermanshah & 5526.5 & 38 & 1250323 & 678648 & 758710 & 51136 & 129644 & 290 & 18567 & 502 & 5 & 108 & 15 \\
\hline 22 & Boyerahmad & 323.5 & 18 & 478000 & 874000 & 199631 & 37360 & 55639 & 154 & 1853 & 42 & 14 & 59 & 1 \\
\hline 23 & Golestan & 497 & 64 & 862825 & 426476 & 606354 & 31947.548 & 55948 & 234 & 23325 & 2552 & 63 & 363 & 14 \\
\hline 24 & Gilan & 1330 & 77 & 244986 & 564712 & 304778 & 115926.2 & 156426 & 2028 & 3612 & 37 & 58 & 158 & 3 \\
\hline 25 & Lorestan & 266 & 31 & 884355 & 1217313 & 357314 & 41196 & 120412 & 328 & 12217 & 180 & 18 & 214 & 6 \\
\hline 26 & Mazandaran & 624 & 66 & 585022 & 1107256 & 425585 & 150684 & 324404 & 1332 & 17790 & 1963 & 15 & 348 & 21 \\
\hline 27 & Markazi & 275 & 4 & 2030203 & 23639 & 379831 & 47200 & 66405 & 248 & 11969 & 227 & 22 & 1564 & 69 \\
\hline 28 & Hormozgan & 153.4 & 12 & 4059900 & 1075894.887 & 76312 & 73498 & 6646 & 66 & 2740 & 17 & 21 & 53 & 1 \\
\hline 29 & Hamedan & 344 & 17 & 822000 & 37704 & 634433 & 60555 & 126044 & 113 & 19839 & 672 & 69 & 276 & 34 \\
\hline 30 & Yazd & 104 & 5 & 6518007 & 183922 & 52391 & 75818.7 & 39923 & 280 & 3025 & 44 & 62 & 1311 & 33 \\
\hline
\end{tabular}

1. Annual rainfall amount, 2. Number of permanent rivers, 3. The width of pastures, 4. The width of forest, 5. Cultivated level of agricultural harvests, 6 . Cultivated level of garden harvests, 7. Number of beehives, 8 . Number of fish farming ranches, 9 . Number of tractors, 10 . Number of combine, 11. Number of cooperative production societies, 12. Number of industrial cattle breeding, 13. Number of industrial aviculture

Table 2

Provinces comparative development rank based on taxonomy method

\begin{tabular}{|c|c|c|c|c|c|c|c|c|c|c|c|}
\hline Row & Province & Coi & $\mathrm{CO}$ & $\mathrm{Fi}$ & RANK & Row & Province & Coi & $\mathrm{CO}$ & $\mathrm{Fi}$ & RANK \\
\hline 1 & East Azarbayjan & 10.21804 & 14.61816 & 0.698997 & 4 & 16 & Fars & 9.170925 & 14.61816 & 0.627365 & 2 \\
\hline 2 & West Azarbayjan & 10.90294 & 14.61816 & 0.745849 & 7 & 17 & Qazvin & 13.46422 & 14.61816 & 0.921061 & 28 \\
\hline 3 & Esfahan & 10.2752 & 14.61816 & 0.702906 & 5 & 18 & Qom & 13.61951 & 14.61816 & 0.931685 & 29 \\
\hline 4 & Ilam & 13.15879 & 14.61816 & 0.900167 & 24 & 19 & Kordestan & 11.48525 & 14.61816 & 0.785683 & 11 \\
\hline 5 & Ardebil & 12.18851 & 14.61816 & 0.833792 & 15 & 20 & Kerman & 10.46646 & 14.61816 & 0.71599 & 6 \\
\hline 6 & Bushehr & 13.65732 & 14.61816 & 0.934271 & 30 & 21 & Kermanshah & 11.20745 & 14.61816 & 0.76668 & 9 \\
\hline 7 & Tehran & 11.69665 & 14.61816 & 0.800145 & 12 & 22 & Boyerahmad & 13.40442 & 14.61816 & 0.91697 & 27 \\
\hline 8 & Bakhtiari & 13.10611 & 14.61816 & 0.896563 & 23 & 23 & Golestan & 11.1328 & 14.61816 & 0.761574 & 8 \\
\hline 9 & North Khorasan & 12.77264 & 14.61816 & 0.873751 & 21 & 24 & Gilan & 11.37584 & 14.61816 & 0.778199 & 10 \\
\hline 10 & Razavi khorasan & 8.763117 & 14.61816 & 0.599468 & 1 & 25 & Lorestan & 12.2891 & 14.61816 & 0.840674 & 16 \\
\hline 11 & South Khorasan & 13.00196 & 14.61816 & 0.889439 & 22 & 26 & Mazandaran & 9.783058 & 14.61816 & 0.66924 & 3 \\
\hline 12 & Khozestan & 11.7396 & 14.61816 & 0.803083 & 13 & 27 & Markazi & 12.35867 & 14.61816 & 0.845433 & 18 \\
\hline 13 & Zanjan & 12.34191 & 14.61816 & 0.844286 & 17 & 28 & Horn & 13.30432 & 14.61816 & 0.910123 & 26 \\
\hline 14 & Semnan & 13.24903 & 14.61816 & 0.90634 & 25 & 29 & Hamedan & 11.99258 & 14.61816 & 0.820389 & 14 \\
\hline 15 & Sistan & 12.58127 & 14.61816 & 0.86066 & 19 & 30 & Yazd & 12.64795 & 14.61816 & 0.865221 & 20 \\
\hline
\end{tabular}


As observed from the results of Table 2, Razavi Khorasan comes first in terms of ranking followed by Mazandaran, East Azarbayjan while Bushehr received the lowest development level. It is surprising to see that the province of Semnan, which is located on the right side of the capital city of Iran maintains a low priority.

\section{Conclusion}

In this paper, we have presented a mathematical model to measure the relative efficiency of different provinces based on agricultural features. The primary concern was to determine the ranking based on taxonomy approach as an MCDM technique. Along with this, data related to annual rainfall amount, the number of permanent rivers, the width of pastures and forest, cultivated level of agricultural and garden harvests, the number of beehives, fish farming ranches, tractors, and combines, the number of cooperative production societies and industrial cattle breeding and aviculture have considered as input indices. The Results of our survey indicated that that Razavi Khorasan maintained the highest development level and Bushehr had the lowest development level.

We have used taxonomy technique in this study. However, we can profit from other existing methods like Data Envelopment Analysis (DEA), Deterministic Frontier Analysis (DFA), Stochastic Frontier Analysis (SFA), and Topsis, which can be applied as a basis for doing future researches.

\section{Acknowledgement}

The author thinks it necessary to acknowledge all people who help accomplishing this study and compiling paper.

\section{References}

Chen, Z., \& Song, S. (2009). Efficiency and technology gap in China's agriculture: A regional metafrontier analysis. China Economic Review, 19(2), 287-296.

Hoang, V.N., \& Rao, D.S.P. (2010). Measuring and decomposing sustainable efficiency in agricultural production: A cumulative exergy balance approach. Ecological Economics, 69(9), $1765-1776$

Hu, J.L., Wang, S.C., \& Yeh, F.Y. (2006). Total-factor water efficiency of regions in China. Resources Policy, 31(4), 217-230.

Judd, W.S., Campbell, C.S., Kellog, E.A., Stevens, P.F., \& Donoghue, M.J. (2007). Taxonomy. In Plant Systematics - A Phylogenetic Approach, $3^{\text {rd }}$ Ed. Sinauer Associates, Sunderland.

Mao, W., \& Koo, W.W. (1997). Productivity growth, technological progress, and efficiency change in chinese agriculture after rural economic reforms: A DEA approach. China Economic Review, $8(2), 157-174$.

Martić, M., \& Savić, G. (2001). An application of DEA for comparative analysis and ranking of regions in Serbia with regards to social-economic development. European Journal of Operational Research, 132(2), 343-356.

Murshed-E-Jahan, K., \& Pemsl, D.E. (2011). The impact of integrated aquaculture-agriculture on small-scale farm sustainability and farmers' livelihoods: Experience from Bangladesh. Agricultural Systems, 104(5), 392-402.

Picazo-Tadeo, A.J., Gómez-Limón, J.A., \& Reig-Martínez, E. (2011). Assessing farming ecoefficiency: A Data Envelopment Analysis approach. Journal of Environmental Management, 92(4), 1154-1164.

Reith, C.C., \& Guidry, M.J. (2003). Eco-efficiency analysis of an agricultural research complex. Journal of Environmental Management, 68(3), 219-229

Sadjadi, S.J., Omrani, H., Abdollahzadeh, S., Alinaghian, M., \& Mohammadi,H. (2011). A robust super-efficiency data envelopment analysis model for ranking of provincial gas companies in Iran. Expert Systems with Applications, 38(9), 10875-10881. 
Sueyoshi, T. (1999). DEA non-parametric ranking test and index measurement: slack-adjusted DEA and an application to Japanese agriculture cooperatives. Omega, 27(3), 315-326.

Sultana, A., \& Kumar, A. (2012). Ranking of biomass pellets by integration of economic, environmental and technical factors. Biomass and Bioenergy, 39, 344-355. 